\title{
Application of Ceramic Sculpture in Public Environment
}

\author{
Lijuan Zhang \\ Zhengzhou University of Light Industry \\ Zhengzhou, China 450002
}

\begin{abstract}
With the rapid economic development, people's living standard is also improved gradually. Art gradually takes the important mission to beautify our lives. As an ancient yet new material, ceramics are re-recognized and used by artists, granting it brand new meaning. Its own meaning has been extended infinitely, which has surpassed its basic practical functions, entering into the public domain and people's vision with a new look, enraging people's spiritual life. And people's appreciation requirement for public art has been enhanced from the initial basic beautiful and practical function to the level of spiritual culture.
\end{abstract}

Keywords - ceramic sculpture; public environment; modern art; architecture

\section{INTRODUCTION}

As a humanistic art, public art has combined time, space, nature, society, humanity and other artistic disciplines. The environmental sculpture is one of the important categories. Ceramic sculpture has become one of the important expression forms in environmental sculpture with its simple and natural features, and has gradually integrates into people's lives. Many new and unique creative direction and forms have appeared for the modern ceramics developed gradually based on traditional ceramics. You can see the wide application of ceramic sculpture, and even modern ceramic murals, ceramic ware, etc. in indoor and outdoor public environment. They are fused in the architectural space and environment perfectly, having enhanced the taste of environmental space, provided people with physical and mental pleasure, cultivated people's sentiments and satisfied modern people's rich spiritual aesthetic needs while beautifying the architectural environment.

As one of the important expression forms of public environmental art, ceramic sculpture expresses this feature with its affinity of focusing more on soil, stressing the integration of sculptures with our social life, and the expression of living emotion of us as human, and the observation, touch and participatory sensing of the appreciators. It can not only show the inspirational and highspirited moments in our social life, but also can show the ordinary and simple, and even the suppressed frustration helpless moment; it can not only allow people to see far away, but also enable them to appreciate nearby, and can get into it to touch, hear, percept, and participate in, to make the works' endless content burst at this moment, and enable the minds and emotions of visitors and creators to be blended here.

\section{CONCEPT OF PUBLIC ENVIRONMENTAL CERAMIC SCULPTURE AND MATERIAL PROPERTIES}

\section{A. Concept of Public Environmental Ceramic Sculpture}

From the perspective of traditional concept, sculpture is a kind of three-dimensional space art, and various different three-dimensional forms (styles of the modeling and description of time-space characteristics), different modeling language (systematic expression means) and the infused different ideologies and emotions, have become the style history of sculpture art as well as the history of ideology evolution. The intervention of ceramic sculpture into public environment is made based on research on modern environmental science, and the special design discipline of ceramics for production process.

The ceramic sculptures for public environment are also established based on the objective materials, with architecture, mechanics and aesthetics as the principles, the creation of ideal living space as the original driving force, the combination with multiple materials as prerequisite, to reasonably use the existing natural resources and create a better virtuous circle for the ecosystem. Taking the original, recycled and the future natural environment as starting point, to coordinate the relationship between natural environment, humanistic environment and social environment in combination with the existing scientific and technological means as well as artistic creative activity, and make them interact, so that they can achieve the best condition of trinity.

Such creative activity covers a particular technological process, such as firing, painting, heterogeneous isomorphism, etc., to create a good humanistic environment, as well as the artistic space integrating human and environment by virtue of different characteristics of other materials through such comprehensive feelings as vision and sense of touch. Such artistic creation requires creators to understand and learn about the environment, emphasize the established artistic feeling conveyed by space atmosphere as well as the original affinity of human and material, pay attention to the entity and respect the creative process, so as to achieve good environment construction.

The concept of Environmental Ceramic Art was first proposed in Japan, Korea and other places in the last decade. Although the creative practice has been made in Europe and America for three decades, they did not put forward the 
concept of "Environmental Ceramic Art". Chinese ceramists also start to introduce this concept in recent years, and it mainly refers to the ceramic art works or the ceramic artoriented integrated media works established in public buildings, building components, squares, parks, roads, green spaces, residential areas, suburban open spaces and other places within urban public spaces. With the impact of contemporary art and development of modern ceramic art itself, it has already gone beyond the narrow definition of "only the fired ceramics can be called ceramic art", and has evolved into that any works with clay as the creative medium, displaying clay's nature of "mud" and "soil" in full can be interpreted as modern ceramic art. Any ceramic art works involved in public environment, communicate and integrate with the environment, as well as interact and exchange ideas with the public fully containing humanistic spirit can be called Environmental Ceramic Art in the contemporary sense.

\section{B. Advantages and Limitations of Ceramics as Environmental Sculpture Material}

Ceramics is an ancient art. Thousands of years of ceramic culture accumulation renders it the excellent qualities such as convenient material drawing, easy processing, solid, wearresisting and corrosion prevention, which enables us not to be surprised that ceramic material has always served an important role in people's real life for thousands of years, no matter it is used for living appliances or funeral objects. For example, pottery figurines are not only the mainstream of funeral objects statue, but also the ceramics closely integrated with the then environment.

Ceramic sculpture is a comprehensive crystallization of science and art. Ceramics has many advantages over other media as the sculpture medium, which are summarized as below:

- Ceramic works is the art of fire. After high-temperature firing, its glazing color can remain unchanged for thousand years, which is the most prominent feature of ceramic material.

- Ceramic works have rich and colorful glazing colors, which can inspire the creators' countless inspiration, and can give the viewer a refreshing feeling.

- Ceramic materials have the characteristics of corrosion resistance, rain-proof and frost-resistance and high temperature resistance, which enable ceramic works not to change due to natural erosion and climate change in terms of its structure. As a result, its structure can maintain for a long time.

- After high temperature firing, the glassy glaze formed on the surface of ceramics is easy to be cleaned, enabling its appearance not to be impact even it is placed in the city with severe pollution. Many of its advantages show that ceramic sculptures are suitable to be placed outdoors for long.

Of course, ceramic sculpture also has its drawbacks, which basically exist in the ceramic production process:
- Friability is the biggest disadvantage of ceramic material. So it has high transportation and installation requirements.

- It is easy to be deformed, with the main problems exist in the process of moulding body drying and firing. The works' installation will be directly influenced if there is any deformation after firing, and some components may even be discarded and recreated. This problem is common for all large-scale ceramic works, which requires high operating skills and rich experience to resolve.

- The manufacture and production of ceramics relies on the climate, which is also a problem exists in the production process of ceramic sculpture. The large ceramic works placed outside often have thick moulding body, which is not easy to dry. Usually, the artificial accelerating drying cannot be adopted, as it is better for them to be dried naturally. However, the moulding bodies are easy to be frost-cracked during their drying process in cold weather.

The whole production process of ceramic sculpture is complex, so any negligence in any link will directly affect the final effect of the firing and post-installation. As a result, we can say any piece of ceramic sculpture is a hard-won achievement.

\section{CurRent Situation of Application of Ceramic} MATERIALS IN PUBLIC ENVIRONMENT AT ALL TIMES AND IN All COUNTRIES

\section{A. Application of Ceramic Materials in Public Environment in China}

The building elements appeared earliest in China that can be verified are the ceramic water pipes in Longshan Culture Period; then came the Qin bricks and Han tiles with simplicity and high decorativeness; the Terracotta Warriors made up of nearly thousands of two-meter high warriors, the majestic military array makes it magnificent, as if the military exploit and military power established by the First Emperor of Qin while he unifying the country is reproduced instantly; the Great Wall entrenching in the mountains outside the Pass like an Oriental dragon fits with the environment seamlessly, which is entirely a great environment ceramic art device and architectural works. The "Nine Dragon Wall" outdoor ceramic art wall of Hongwu Period of Ming Dynasty, which is now stored in the Palace Museum and was built in the 38th year of Qianlong administration can be regarded as the model of urban sculpture of ancient China. It is 20.40 meters long, 3.50 meters high, and the facade consists of 270 pieces of fired plastic glass blocks, and in order to highlight the image of the dragon, craftsmen shaped, manufactured and fired it using the technique of high relief, with the three-dimensional sense; in addition, the doll building walls in Foshan Ancestral Temple, the ancient glass tiles and the ceramic rosefinch basaltic roofs that are located all over the world are all the excellent representatives of ancient architectural art. 
Today, we can see the ceramic tiles and ceramic jars with unique style everywhere in Shaanxi Chenggu and the small town and dwellings within Guantong Ceramic Area of Hunan Province.

The world's first Ceramic Art Wall Hanging of Shanghai Oriental Art Center is a successful example of ceramic art being integrated into the building environment. The special ceramic mural of "Eternal Rhythm" created by Chinese muralist Mr. Liu Yu'an has overcome and resolved the gridlike stiffness and cautiousness formed by the square and rectangular arrangement types of traditional mural' flat combination forms, which has narrowed the gap between China's ceramic mural and that of Japan and other developed countries. The environmental ceramic mural of "Mountain Spirit Water Soul" created by Mr. Yuan Yunfu for Chinese Academy of Social Sciences is the representative works integrating painting and color glaze decoration.

"Light of Life" designed by Professor Zhu Yuegeng for art museum of Korean Seoul Grain Concert Hall forms the mural with square geometric blocks with different sizes and rich rhythm changes, the rich and implicit dark glazing colors such as golden, orange, yellow grey, olive green and earthy red... flowing and changing, which are gorgeous and twinkling as well as gentle and peace, as if the flow of time and a ripe fruit, which has completed the "imagination of time and space."

Another example, Mr. Huang Huanyi designed and completed two sets of large-scale environmental ceramic art of "Door" and "Framing" at the entrance of Jingdezhen City Airport in 2004, of which the works of "Door" is stored in the museum of American Alfred University. Such series largescale outdoor environmental ceramic art has become the landmark of Jingdezhen City.

\section{B. Creations of Western Artists in Public Ceramic Sculpture}

The ceramic sculptures created by the Italian ceramist and sculptor Lucca Della Robbia in the 15th century can be considered as a sprout of ceramic sculpture being used in the public environment. His works are generally placed in the construction environment, giving full consideration to and constructing in accordance with the building's structure and space environment. Even today, we can still see a lot of his ceramic sculptures distributing fresh life breathing on the front walls of churches, chapels and some non-religious buildings in the city of Florence.

The famous Spanish architect Antoni Gaudi i Cornet can be said the architect using the most ceramic material in history. Gaudi often made collages using the beautiful painted ceramic pieces, combining the colorful ceramic decoration with the magical design of building perfectly. Wavy curves and ceramic decoration are the signs of Gaudi. In addition to the ceramic collage decoration attached to the building, we often see some independent landscape sketches made up by ceramic materials, for example, the design of conch-shaped staircase on the roof terrace of Casa Mila.

Another artist who has huge contributions to the environment ceramic sculpture is Spanish Joan Miró. His representative works - the giant ceramic mosaic sculpture of
"Taroinsect" located in front of Sants Train Station, Barcelona, Spain, makes metonymy by meaning of silkworm chrysalis into butterfly, meaning the birth of life, namely people are liberated from the dark dictatorship under Franco. The works of "Woman and Bird" standing in the street of Barcelona is also its classic works of ceramic mosaic sculpture.

The Bossy Trim Floor Tile Relief Wall created and completed by famous British sculptor Henry Moore in the 1950s in England is also the excellent example ceramic art's application in public environment.

\section{VAlUE AND SignifiCANCE OF CERAMIC SCULPTURE IN PUBLIC ENVIRONMENT CREATION}

People's walking space is occupied by the public transport due to modern development, and the gap between rapid development of building and the development pace of people's lives is widened gradually. As a reflection of this phenomenon, more and more cities establish squares and flower beds as well as sculptures in many places, so as to restore human living space more effectively. As the behavioral expression closely interacted with people, public environmental sculpture has drawn great importance. Sculpture is the outstanding creative achievements of people, expressing the desire to restore the lost humanity in city with important meaning of existence.

The significant feature of environmental ceramic sculpture is that it shall be placed in a specific environment, and shall be coordinated with the surrounding environment. A good sculpture is often the product of the interaction between and the organic combination of environment and sculpture. On the one hand, it is subject to environment, and shall consider specific environment in terms of subject matter, size, style formulation and selection, and remain a harmonious and integrated relationship with it; on the other hand, it also affects the surrounding environment, improves the cultural taste of the space and improves our environmental quality.

The artistic conception value of public ceramic sculpture lie in that we shall give the used ceramic material life, and deal with the relationship between reality and nature. Its art aesthetic value is to expand its existence space to corresponding items, and form an artistic conception, enabling people to generate a feeling and understanding with rich philosophical thought. As a material form with the most affinity, ceramic sculpture is certainly to display its value in the macro and realistic field of public environment design, so that more people can have the personal understanding and experience.

The core concept of contemporary public art design is "people-oriented" to meet people's evolving aesthetic needs. Therefore, when the modern ceramic art has become an important component of the public environment, the intimacy expressed by ceramics' feature of mud, the richness presented by the colorful glazing colors, and the newly introduced methods have shortened the sense of distance between the works effect and our perception of objects, conveying people's aesthetics and enjoyment. The unique charm generated by the artistic combination of ceramic material with "fire" by virtue of its features of simple, natural and freedom adds unlimited profound meaning to the works, which has greatly enriched the 
diversity of public art. The contemporary ceramic art itself develops together with the contemporary art, which is also an important part of contemporary art.

Like other forms of art, ceramic sculpture is a kind of expression of personal feelings and the re-excavation of personal inner world and spiritual world. Its creative process is a kind of personal artistic behavior under kind of pure free situation. When ceramic sculpture enters into public environmental art, and became one of the constituent elements, it is bound to be restricted by public environment and many other factors. The ceramic sculptures in public environment have complex processes that cannot be omitted, making it have to permeate into the common problems faced by other sculptural forms, thus its design meaning becomes a double meaning. First, its design meaning in this area naturally integrates many factors, and becomes complicated and integrated. Second, it also faces the space existence form to construct architectural natural environment with ceramics as medium, therefore, it requires a comprehensive and threedimensional perspective thinking of the potential severe test brought by various links. In this case, the ceramic sculpture in public environment has proposed a better design thinking proposition for the environmental artistic design in a general sense in on the one hand, on the other hand environmental artistic design has brought about a wider space for the realization of ceramic material, which is ancient yet novel.

The practical significance brought by ceramic sculpture design in public environment not only includes the creation and placement of physical forms in the space, but also lay more emphasis on people's behavioral regulation in space and time state, which is a creation for others. The feature of forothers of creation enables ceramic sculpture to transform into a kind of for-others design artistic form from the original pure humanistic artistic creation form upon its entering into public environment.

\section{OUTLOOK APPLICATION AND DEVELOPMENT OF CERAMIC SCULPTURE IN PUBLIC}

In the modern society with rapid development of information and mutual cross of architecture, the Eastern and Western culture penetrates mutually, with transplantation and integration. The international plurality forms tend to be universal harmony, the boundary and definition between specific artistic classes has become increasingly blurred, crossdisciplinary and cross-border, integrating and absorbing mutually around the world. What emerges at the right moment is our "ancient" newborn - Chinese modern ceramic art. In order to make it grow healthily, we need to continuously study and expand its infinite application possibility with efforts positively on the one hand, and on the other hand, it also requires us to try our best to cultivate it.

The Chinese ceramic sculpture in public environment starts late, but it develops rapidly in recent years. In the development in the future, first of all, we shall carry forward our nation's excellent ceramic culture based on the profound ceramic achievements accumulated since the ancient times, and fit the spirit of the times. At the same time, communicate with the artistic circles such as environmental artistic circle and ceramic industry, and try to integrate into the mainstream of international ceramics and public environment. Second, we shall take initiative to develop and carry out the ceramic sculpture series activities with Chinese characteristics in public environment in combination with the national conditions and according to their own development needs, to show the unique charm of contemporary Chinese ceramic sculpture, so as to shine splendor in the international ceramic sculpture and public environment. Third, the Chinese ancient cultural heritage should be fully excavated and displayed, and get into the contemporary artistic creation in-depth, combining theory and practice. It shall develop in the process of carrying forward, and carry forward in development, and introduce the excellent foreign achievements on this regard scientifically, to absorb and refer to the essence of the works of domestic and foreign ceramists, public environmental artists and architects combining Chinese ceramic features with high-standard scientific attitude, so that the ceramic sculpture may continue to shine in the field of public environment.

When the monotony and apathy are questioned as one of the social phenomena, the natural, ecological, humane, poetic and personalized architectural and environmental space is being called and expected.

\section{REFERENCES}

[1] (UK) Herbert Read. Modern Sculpture: A Concise History. Sichuan Fine Arts Publishing House, 1989.9.

[2] Lei Junliang. Regional Fitness of Urban Sculpture. Xi'an Academy of Fine Arts, 2007.

[3] Wayne Higby. Mutual Learning of Ceramic Art. Foreign Contemporary Ceramic Art Classics. Jiangxi Fine Arts Publishing House, 2004.6.

[4] Shi Di. Discussion on Combination of Ceramic Art and Environmental Art, 2006.6

[5] Gong Baojia. Cultural Reflection on Ceramic Sculpture' s Intervention in Public Environmental Art. 2006.10.

[6] Lin Zibo, Zhao Lantao. Reflection on Public Sculpture [J].Decoration. 2004 (09). 